\title{
Örgütsel Adalet Algısı ve Örgütlerde İntikam Niyeti Arasındaki İlişkiyi Belirlemeye Yönelik Bir Araştırma*
}

\author{
Işıl USTA \\ Trakya Üniversitesi, Sağllk Bilimleri Fakültesi, Sağlık Yönetimi Bölümü, \\ isilusta@trakya.edu.tr, ORCID:0000-0003-2527-2961 \\ Serol KARALAR \\ Sorumlu Yazar, Trakya Üniversitesi, Sağllk Bilimleri Fakültesi, \\ Sağlık Yönetimi Bölümü \\ serolkaralar@trakya.edu.tr, ORCID:0000-0003-3460-207X \\ Tülay DEMIIRALAY \\ Trakya Üniversitesi, Keşan Yusuf Çapraz Uygulamalı Bilimler Yüksekokulu, \\ Bankacılık ve Sigortacılık Bölümü, \\ tulaydemiralay@trakya.edu.tr, ORCID:0000-0001-8284-6699

\begin{abstract}
Öz
Her çalışan kendi yaptığı iş, aldığı ücret, ödül, ceza, yöneticilerinin kendisine gösterdiği davranış gibi unsurlar ile diğer çalışanların sahip olduğu unsurları ve onlara karşı gösterilen davranışları karşılaştırarak örgüt içinde adalet olup olmadığı sonucuna ulaşmaktadır. Örgütte adaletsizliğin var olduğunu düşünen çalışan, intikam eğiliminde bulunma gibi olumsuz duygular geliştirebilmektedir. İntikam, örgüt içinde istenmeyen, örgüte zarar veren bir durum olup çalışan, intikam sonucunda mağduriyetini giderme ve adaleti sağlama beklentisi içerisine girebilmektedir. Kavramların sahip olduğu önem doğrultusunda bu çalışmanın amacı; örgütsel adalet algısının örgütlerde intikam niyeti üzerindeki etkisinin incelenmesidir. Bu amaçla, bir devlet üniversitesinin 4 yıllık eğitim veren fakülte ve yüksekokullarında araştırma görevlisi kadrosunda görev yapan 154 kişi üzerinde bir anket çalışması yürütülmüştür. Yapılan lojistik regresyon analizi sonucunda araştırma görevlilerinin intikam niyeti ve örgütsel adalet algıları arasında istatistiksel olarak anlamlı bir ilişki bulunmamış olmakla birlikte intikam niyetini, süreçler ve kişilerarası etkileşimlerdeki adaletten çok dağıtım adaletinin etkileyebileceği tespit edilmiştir.
\end{abstract}

Anahtar Kelimeler: Örgütsel Adalet Algısı, İntikam Niyeti, Araştırma Görevlisi.

JEL Sinıflandırmasi: M10, D23, J20

A Research on Determining the Relationship between Organizational Justice Perception and Revenge Intention in Organizations

\begin{abstract}
By comparing factors such as their own jobs, wages, rewards, penalties, behaviors directed from managers, and other employees' factors and behaviors directed to them, employees conclude if there is justice in the organization or not. An employee might develop negative emotions such as intention of revenge if he/she thinks that injustice exists in the organization. While revenge is an unwelcome and harming situation in the organization, an employee might expect to relief and secure the justice as a result of revenge. Accordingly, the purpose of this study is to reveal whether organizational justice perception has effects on revenge intention in the organizations or not. For this purpose, a survey was conducted on 154 research assistants working at four-year faculties and colleges of a state university. After logistic regression analysis, it was found that instead of procedural and interpersonal justice; distributive justice might affect revenge intention even though there isn't statistically significant relationship between research assistants' revenge intentions and perceptions of organizational justice.
\end{abstract}

Keywords: Organizational Justice Perception, Revenge Intention, Research Assistant.

JEL Classification: M10, D23, J20

\footnotetext{
* Bu çalışma, 15. Ulusal İşletmecilik Kongresi'nde bildiri olarak sunulmuş olup veriler başka bir analiz tekniği ile değerlendirilmiştir.

${ }^{\dagger}$ Extended abstract is presented at the end of the article.
}

Geliş Tarihi (Received): 28.11.2018 - Kabul Edilme Tarihi (Accepted): 30.12.2019

Atıfta bulunmak için/Cite this paper:

Usta, I., Karalar, S. ve Demiralay, T. (2019). Örgütsel adalet algısı ve örgütlerde intikam niyeti arasındaki ilişkiyi belirlemeye yönelik bir araştırma. Çankırı Karatekin Üniversitesi İBFF Dergisi, $9(2), 535-557$. 


\section{Giriş}

Örgütlerin yaşamlarını devam ettirmelerini sağlayan unsurlardan bir tanesi sahip oldukları çalışanlardır. Çalışanların, bulundukları örgütte kalıp kalmama kararları, ihtiyaçlarının ve beklentilerinin karşılanma derecesine, örgüte ve uygulamalarına ilişsin algılarına bağglı olabilmektedir. Çalışanların örgütlerdeki adalet algısı, örgüt içindeki tutum ve davranışları üzerinde önemli bir etkiye sahip olmaktadır (Greenberg ve Colquitt, 2005, s. 330). Bu nedenle sosyal bilimciler, etkili örgüt işlevleri ve çalışanların kişisel tatminleri için temel gereklilik olan adaletin önemini tanımlamaya çalışmaktadırlar (Greenberg, 1990, s. 399). Çalışanların tatmin edilmesi; örgüte olan bağlılık ve sadakatlerinin kazanılması için gerekmekte olup bunların sağlanabilmesinde örgütün ihtiyacı olan ise adil bir sistemin oluşturulmasıdır. Çalışanlar örgüt tarafından kendilerine adil davranıldığını hissettiklerinde bağlılık ve tatmin olma gibi daha olumlu tutum ve davranışlar göstermeye eğilimli olacaklardır (Akanbi ve Ofoegbu, 2013, s. 207; Bakhshi, Kumar ve Rani, 2009, s. 145). Bu durumun aksi gerçekleştiğinde ise çalışanlar örgüt içinde olumsuz tutum ve davranışlar gösterebileceklerdir. Çalışanlar, örgüt içinde mağdur olduklarını anladıklarında bu durum tutum ve davranışlarına yansıyacak ve mağduriyetlerini gidermek için intikam niyetinde olabileceklerdir (Akın, Özdevecioğlu ve Ünlü, 2012, s. 78).

İntikam niyeti örgütsel davranış yazınında çok fazla incelenmemekle birlikte bu çalışmada çalışanların örgütsel adalet algılarının intikam niyetlerine etkisinin ortaya koyulması amaçlanmıştır. Çalışmada öncelikle örgütsel adalet algısı ve intikam niyeti kavramları açıklanmış daha sonra iki kavram arasındaki ilişkiyi ortaya çıkarabilmek için uygulanan anket çalışmasından elde edilen bulgulara yer verilmiştir.

\section{Literatür Taraması}

Adalet ya da adillik kavramları ile ilgili yapılan çalışmaların Plato ve Socrates zamanlarına kadar dayandığı ve adalet kavramının, "doğruluk" ya da "dürüstlük" anlamlarında kullanıldığı belirtilmektedir (Colquitt, Conlon, Wesson, Porter ve $\mathrm{Ng}, 2001$, s. 425). Örgütsel adalet ise, Adams tarafından 1960 yılında ortaya atılan Eşitlik Teorisi ile gündeme gelmeye başlamıştır (Cihangiroğlu, 2011, s. 9; Gürbüz ve Mert, 2009, s. 118). Eşitlik teorisine göre; kişinin tatmin olma derecesi ve başarısı, çalıştığı ortam ile ilgili eşitlik algısına bağlı olmaktadır (Luthans, 2011, s. 170). $\mathrm{Bu}$ doğrultuda eşitlik teorisinde çalışanların örgüt içindeki adalet algılamalarının öne çıktığı söylenebilir. Dolayısıyla örgütsel adalet, çalışanların işlerinde adil davranma veya adalet algılamaları ile ilgili olmaktadır (Fox, Spector ve Miles, 2001, s. 294).

Endüstriyel ve örgütsel psikoloji, insan kaynakları yönetimi ve örgütsel davranış bilim alanlarında en çok araştırılan konulardan biri, örgütlerde çalışanların adalet algılamaları anlamına gelen örgütsel adalet konusudur. Adalet algılaması 
denilince, örgüt politikalarında, ödeme sistemlerinde ve bireysel uygulamalarda adillik anlaşılmaktadır (Cropanzano ve Greenberg, 1997, s. 3). Örgütsel adalet, örgüt içerisinde ücretlendirmenin, ödüllendirmenin, cezalandırmanın, terfi uygulamalarının, yetkilendirmenin, görev dağılımlarının vb. kararların ne şekilde gerçekleştirileceği ve bu kararların nasıl alındığı, kararların çalışanlara aktarım şekli ve çalışanların bu kararları algılama biçimi olarak ifade edilmektedir (İyigün, 2012, s. 51; İçerli, 2010, s. 69).

İlgili yazında örgütsel adaletin boyutları konusunda bir uzlaşma sağlanamadığı anlaşılmaktadır. Örgütsel adalet ile ilgili yapılan çalışmaların genellikle adaletin iki büyük ve önemli şekli olan dağıtım adaleti ve işlemsel (prosedürel) adalet üzerinde durduğu görülmektedir (Fox vd., 2001, s. 294; Cropanzano ve Greenberg, 1997; Lowe ve Vodanovic, 1995, s. 100; Folger ve Konovsky, 1989). 1975 yılından önce adalet ile ilgili yapılan çalışmalar dağıtım adaletine odaklanmakta olup çalışmaların çoğunluğu adaleti değerlendirmede sosyal karşılaştırma teorisini temel alan Eşitlik Teorisinin yaratıcısı Adams'tan kaynaklanmaktadır. Buna göre; kişinin kendi kazanımları ve katkıları ile başkasının kazanımları ve katkılarını karşılaştırması sonucunda elde edilen kazanımların adil olup olmadığ 1 algılanmaktadır (Colquitt vd., 2001, s. 426). Bu doğrultuda, çalışanın örgüte sağladıkları karşılığında ödüllendirilme, terfi ve prim alma, yetkilendirilme, cezalandırılma, rütbe düşürülme gibi elde ettiği olumlu ya da olumsuz kazanımlarını adil olarak algılamasının dağıtım adaletini ifade ettiği söylenebilir. İşlemsel adalet ise çalışanların, kazanımların belirlenmesi, tanımlanması ve dağıtılması ile ilgili kararların alınma süreci ile ilgili yargılarına dayanmaktadır (Buluc ve Güneş, 2014, s. 147; Moghimi, Kazemi ve Samie, 2013, s. 124; Folger ve Konovsky, 1989, s. 115).

Çalışanın adalet algısında, örgütsel prosedürlerin uygulanışı sırasında kişiler arası ilişkilerin kalitesinin önemli olduğuna odaklanılmış ve bu doğrultuda, iki boyuta ek olarak etkileşim adaleti boyutu geliştirilmiştir (Bakhshi vd. , 2009, s. 147). Greenberg (1993), teorik olarak dağıtım adaleti ve işlemsel adalet yanında etkileşim adaletinin iki alt boyuta ayrılması gerektiğini belirtmiş ve bu düşünce test edilerek, Colquitt (2001, s. 386-400) örgütsel adaletin, dağıtım adaleti, işlemsel adalet, kişilerarası adalet ve bilgisel adalet olmak üzere dört alt boyuta sahip olduğunu ileri sürmüştür. Etkileşim adaletinin kişilerarası ve bilgisel adalet olmak üzere birbirinden bağımsız etki gösteren iki boyuttan oluştuğu belirtilmektedir (Colquitt, 2001, s. 390). Kişilerarası adalet, karar vericilerin karardan etkilenen çalışanlara nazik ve saygılı davranıp davranmadığı, doğru sözlü olup olmadığı ile, bilgisel adalet ise dağıtım kararlarının altında yatan mantığın çalışanlara açık ve yeterli derecede açıklanıp açıklanmadığı ile ilgili olmaktadır (Cihangirlioğlu, 2011, s. 10; Paterson, Green ve Cary, 2002, s. 394). Dolayısı ile, alınan kararların, kararların alınma sürecinin, kararların çalışanlara aktarılma şeklinin ve kararların altında yatan nedenlerin açıklanmasında adalet algısının önemli olduğu söylenebilir. 
Örgütsel adalet, örgütün başarısında önemli ve belirleyici bir faktör olarak gösterilmektedir (Akanbi ve Ofoegbu, 2013, s. 207). Bu nedenle örgütsel adaletin, ilgili yazında birçok kavram ile birlikte incelendiği görülmektedir. Algılanan örgütsel adalet ile örgütsel bağl11ık (Buluc ve Günes, 2014; Latan ve Ramli, 2014; Mete ve Serin, 2014; Bağc1, 2013), sadakat (Radmanesh, 2015; JenaAbadi ve Mobasheri,2014), iş tatmini (Bakhshi vd., 2009; Özer ve Urtekin, 2007), örgütsel vatandaşlık davranışı (Sjahruddin, Sudiro ve Normajati, 2013; İnce ve Gül, 2011), işgören performansı (Kalay, 2016), liderlik (Ngodo, 2008), işten ayrılma niyeti (Rai, 2013), tükenmişlik (Pelit ve Bozdoğan, 2014), örgütsel destek (Tokgöz, 2011), örgütsel ses ve sessizlik (Demiralay, 2014) kavramları arasındaki ilişkiyi inceleyen çalışmalara rastlamak mümkündür. Görüldügü gibi, örgütsel adalet kavramının öncülleri ve sonuçları oldukça fazladır. Örgütsel adalet ile ilgili değişkenlerden bir tanesinin de intikam kavramı olduğu belirtilebilir.

İntikam, temel insani bir dürtü ve sosyal davranışlarda güçlü bir güdüleyicidir (Bradfield ve Aquino, 1999, s. 608). İntikam, algılanan yanlışlığın karşılığında ceza verme olarak tanımlanmakta ve insanın saldırganlığını güdüleyen bir faktör olarak belirtilmektedir (Stuckless ve Goranson, 1992, s. 25). İntikam, örgütte işyeri saldırganlığı şemsiye terimi altında yer almakta olup örgütte intikam, diğer işyeri saldırganlığı kavramlarından farklı olup; sözlü, fiziksel, gizli-kapaklı, açık, direkt, dolaylı, kişiler arası ve örgüte yönelik olmak üzere saldırgan davranışların her türünü kapsamaktadır (Bies ve Tripp, 2005). İntikam davranışı, algılanan örgütsel adaletsizlik ve eşitsizliği gidermeye yönelik bir davranış olup çalışan intikam alınca adaleti yeniden sağladığını düşünmektedir (Akın vd., 2010, s. 79). İntikam niyetinde olan çalışan, amaçları engelleme, kurallara ve normlara uymama, statü ve güce zarar vermeye çalışarak bu niyetini gerçekleştirmektedir (Tripp, Bies ve Aquino, 2007, s. 15).

Kişinin intikam eğiliminde olmasının altında yatan temel neden, eşitsizliği düzeltme düşüncesidir (Stillwell, 2008, s. 259). İntikam, kurbana (intikam niyetinde olan), kabahatliye (yanlış davranışta bulunan) ve aralarındaki ilişkiye zarar vermekte ve kabahatliye yönelik onur kırıcı, aşağılayıcı ve küçük düşürücü sonuçlar yaratmaktadır (Bradfield ve Aquino, 1999, s. 609). Bu sonuçlar aslında kurban tarafından elde edilmek istenen sonuçlardır. İntikam, kızgınlık ve düşmanlık gibi duyguları da beraberinde getirmekte ve bu duygular erken ölümler, bağışıklık sistemi ve koroner kalp rahatsızlıkları gibi sağlık açısından olumsuz sonuçlara neden olabilmektedir (Little, Simmors ve Nelson, 2007, s. 247). Akın, Özdevecioğlu ve Ünlü (2012) tarafından yapılan çalışmada intikam niyeti ile çalışanların ruh sağlığını olumsuz etkilediği sonucuna ulaşılmıştır. Dolayısıyla intikamın, hem kabahatli hem de kurban için fiziksel ve duygusal anlamda olumsuz sonuçlara neden olduğu söylenebilir. Kişisel ve örgütsel düzeyde olumsuz sonuçların önüne geçilebilmesi için eşitliğin ve adaletin olduğu bir örgüt ortamının gerekliliğinden söz edilebilir. Çünkü çalışan, bir adaletsizlik 
fark ettiğinde, kendisine yanlış yapıldığını düşündüğünde bunun karşılığını almak için intikam eğiliminde olabilir.

İntikam, olumsuz yanlarının yanında yapıcı ve toplum yanlısı olarak değerlendirilmektedir. İntikamın, intikam niyetinde olan kişinin özsaygısını onardığı, kaynakların adaletsiz dağıtımını düzeltmeye yönlendirdiğgi, otorite konumundakiler ve örgütsel karar vericiler tarafından kötüye kullanılan güce karşılık güçlü bir caydırıcı olduğu belirtilmekte (Bies ve Tripp, 2001, s. 199) ve yapısal değişiklikler için etkili bir güdüleyici olduğundan söz edilmektedir (Bies ve Tripp, 1996, s. 247). Örgüt içinde çalışanın intikam eğilimde olduğu anlaşıldığında, bazı noktalarda yanlış giden bir şeyler olabileceğini göz önünde bulundurulmasının ve bunları giderebilmek için değişiklikler yapılması yönünde kararların alınmasının gerekli olduğu söylenebilir. Bu doğrultuda intikam eğiliminin, örgütün iyileştirilmesi yönünde bir gösterge olacağı belirtilebilir.

Örgütte adaletsiz bir durum meydana geldiğinde, çalışanlar intikam eğiliminde olabilecekleri gibi, uzlaşma, uzak durma ya da affetme niyetlerinde de olabilmektedirler. Bunlardan hangisinin seçileceği, intikam alma firsatı, kurban ve kabahatli arasındaki ilişkilerin yakınlığ kabahatli arasındaki güç farklılıkları ve örgütsel normlar gibi unsurlara bağlı olarak değişmektedir. Kabahatliye göre kurbanın gücü fazlaysa, işlemsel adalet iklimi yoksa ve kişi olumsuz duygulanıma sahipse diğer kişilere göre daha fazla intikam eğilimde olacaktır (Tripp vd., 2007, s. 13-14). Hem kişisel özelliklerin, hem kişilerarası ilişkilerin ve çalışılan ortamın intikam üzerinde belirleyici bir etkisi olduğunu söylemek mümkündür.

İntikam ile ilgili yerli yazında çok fazla çalışma bulunmamakla birlikte; intikam niyeti ile tükenmişlik, bağlllık, affetme ve olumlu/olumsuz duygu (Little vd., 2007), örgütsel adalet ve zarar verici iş davranışları (Jones, 2009), affetme eğilimi (Yılmaz, 2014; Akın vd., 2012), ruh sağlığı (Akın vd., 2012), örgütsel sinizm, stres ve işten ayrılma niyeti (Özer, Sonğur, Kar, Top ve Erigüç, 2014), izlenim yönetimi (Şener, Çetinkaya ve Akkoca, 2017), işyeri arkadaşlığı (Karacaoğlu, Aksoy ve Şahin, 2018), örgütsel dedikodu (Şantaş, Akbolat ve Sağlam, 2019) kavramlarını karşılaştıran çalışmalara rastlanmıştır.

\section{Araştırma Metodolojisi}

\subsection{Araştırmanın Amacı ve Önemi}

Araştırmanın amacı çalışanların algıladıkları örgütsel adaletin örgüt içindeki intikam niyetlerine etkisini değerlendirmektir. Çalışanlar, adil bir sistemin olduğu ortamlarda çalışmak isterler aksi takdirde herhangi bir adaletsizlik algılarlar ise buna karşı çeşitli tepkilerde bulunabilirler. İntikam da çalışanların adaletsizliğe karşı gösterdiği bir tepki olup hem intikam almak isteyeni hem intikam alınmak isteneni hem de örgütün genel performansını olumsuz açıdan etkileyebilir. 
Dolayısı ile böyle bir durumun hılı ve etkili bir şekilde çözülmesi gerekmektedir. $\mathrm{Bu}$ nedenle çalışanların adalet algıları ile intikam niyetleri arasındaki ilişki incelenmeye uygun görülmüştür.

\subsection{Araştırmanın Evreni ve Örneklemi}

Algılanan örgütsel adaletin intikam niyetine etkisinin ortaya çıkarılması amacı ile yürütülen araştırmanın evreni, bir devlet üniversitesinin 4 yıllık eğitim veren fakülte ve yüksekokullarında araştırma görevlisi kadrosunda görev yapmakta olan çalışanlardan meydana gelmektedir. Bu doğrultuda devlet üniversitesinin web sitesinde yer alan bilgilere göre araştırmanın evrenini 269 araştırma görevlisi oluşturmaktadır. Belirlenen araştırma evreninden elde edilecek örneklem büyüklüğünün, araştırmaciların genel olarak kabul ettiği \%95 güvenilirlik düzeyinde $\mathrm{n}=151(\mathrm{~N}=250)$ ile $\mathrm{n}=168(\mathrm{~N}=300)$ arasında olmasının yeterli olacağ1 söylenebilir (Cohen, Manion ve Morrison, 2007, s. 104). Dolayısıyla kolayda örneklem yöntemi ile seçilen ve araştırmaya katılmayı kabul eden 154 araştırma görevlisinden oluşan araştırma örnekleminin uygun olduğu belirtilebilir.

\subsection{Araştırmanın Sınırlılıkları}

Bilimsel çalışmaların en doğru sonuçlara ulaşmalarını engelleyen bir takım sınırlılıklar bulunmaktadır. Bu çalışmanın temel sınırlılığı ise tek bir üniversitede gerçekleştirilmiş olması ve sadece araştırma görevlisi kadrosunda görev yapanlara uygulanmış olmasıdır. Zaman kısıtı nedeniyle bu sinırlılık unsuru ortadan kaldırılamamıştır. Söz edilen temel sınırlılığın yanı sıra; anket çalışmasının araştırma evreninin tamamına uygulanamaması araştırmanın diğer sınırlılığını oluşturmaktadır.

\subsection{Araştırmada Kullanılan Ölçme Araçları}

Araştırmada veri toplamak amacı ile anket yöntemi kullanılmıştır. Kullanılan anket üç bölümden oluşmaktadır. Anketin birinci ve ikinci bölümünde çalışmanın ana kavramlarından olan örgütsel adalet algısını ortaya koymak amacı ile Colquitt (2001) tarafindan oluşturulmuş ve Özmen vd. (2007) tarafindan Türkçe'ye çevrilmiş 20 ifadeden oluşan 5'li Likert (1=kesinlikle katılmıyorum .... $5=$ kesinlikle katılıyorum) ölçeği ve kişilerin intikam niyetini belirlemek amacı ile Wade (1989) tarafından geliştirilen, Özer vd. (2014)'ün kullandığı ve Akın vd. (2012) tarafından Türkçe'ye çevrilen 5 ifadeden oluşan 5'li Likert (1=kesinlikle katılmıyorum .... 5=kesinlikle katılıyorum) intikam niyeti ölçeği yer almaktadır. Anketin üçüncü bölümünde, katılımciların demografik özelliklerini belirleyebilmek amaciyla 5 soru sorulmuştur. 


\subsection{Araştırmanın Modeli ve Hipotezleri}

İlgili yazında, araştırma kapsamında irdelenen değişkenlerin aralarında bir ilişki kurulabilmesinin ardından araştırma modeli geliştirilmiştir. Araştırma modeline Şekil 1'de yer verilmiştir.

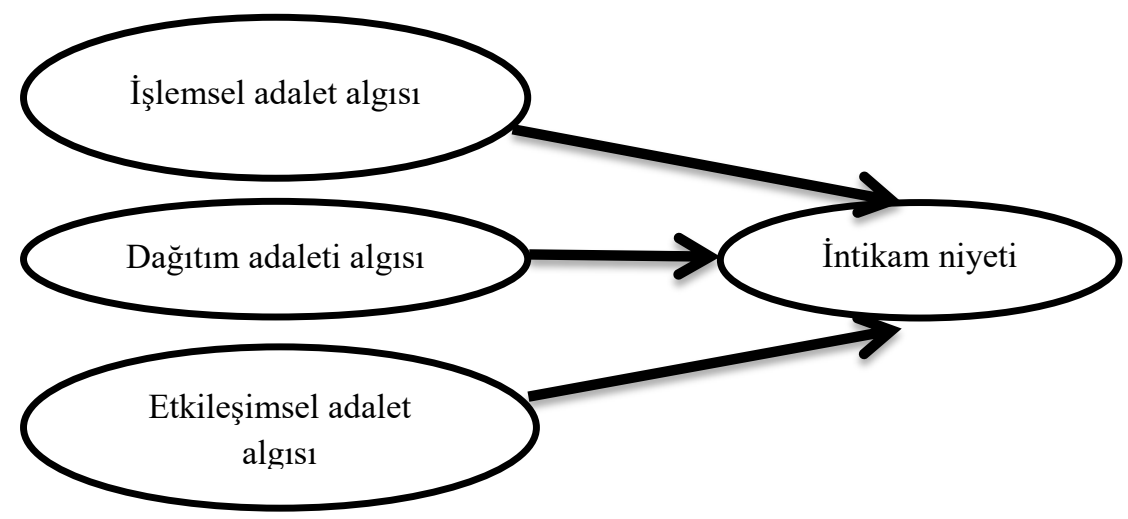

Şekil 1: Araştırma Modeli

Şekil 1'de görüldügü gibi; araştırma kapsamında katılımcı işlemsel adalet, dağıtım adaleti ve etkileşimsel adalet algısı boyutlarının intikam niyeti üzerindeki etkisi incelenmektedir. Oluşturulan model doğrultusunda, araştırmada test edilmek istenen hipotezler ortaya koyulmuştur. Araştırma modeli doğrultusunda geliştirilen araştırma hipotezleri Tablo 1'de gösterilmiştir.

Tablo 1: Araştırmanın Hipotezleri

$\mathrm{H}_{0-1}$ : Katılımcıların adalet algısının intikam niyeti üzerine anlamlı etkisi yoktur.

$H_{1-1}$ : Katılımcıların adalet algısının intikam niyeti üzerine anlamlı etkisi vardır.

$\mathrm{H}_{0-2}$ : Katılımcıların işlemsel adalet algısının intikam niyeti üzerine anlamlı etkisi yoktur.

$\mathrm{H}_{2-2}$ : Katılımcıların ișlemsel adalet algısının intikam niyeti üzerine anlamlı etkisi vardir.

$\mathrm{H}_{0-3}$ : Katılımcıların dağıtım adaleti algısının intikam niyeti üzerine anlamlı etkisi yoktur.

$\mathrm{H}_{3-3}$ : Katılımcıların dağıtım adaleti algısının intikam niyeti üzerine anlamlı etkisi vardir.

$\mathrm{H}_{0-4}$ : Katılımcıların etkileşimsel adalet algısının intikam niyeti üzerine anlamlı etkisi yoktur.

$\mathrm{H}_{4-4}$ : Katılımcıların etkileşimsel adalet algısının intikam niyeti üzerine anlamlı etkisi vardır. 


\subsection{Araştırmanın Bulguları}

Araştırma görevlileri üzerinde uygulanan anketten elde edilen veriler SPSS 22.0 ve AMOS 23 paket programları kullanılarak değerlendirilmiş ve ortaya çıkan sonuçlar yorumlanmıştır. Sonuçların elde edilmesinde açıklayıcı ve doğrulayıcı faktör analizi ile lojistik regresyon analizinden yararlanılmıştır. Tablo 2'de araştırma katılımcılarının sosyo-demografik özelliklerine göre dă̆ılımına yer verilmiştir.

Tablo 2: Katılımcıların Sosyo-Demografik Özellikleri

\begin{tabular}{|c|c|c|c|c|c|}
\hline Cinsiyet & Frekans & $\%$ & $\begin{array}{c}\text { Kurumda } \\
\text { çalıșma süresi }\end{array}$ & Frekans & $\%$ \\
\hline Kadın & 76 & 49,4 & $1-5$ y1l & 95 & 61,7 \\
\hline Erkek & 78 & 50,6 & & & \\
\hline Toplam & 154 & 100 & $0-10$ y11 & 41 & 20,6 \\
\hline Yaş & Frekans & $\%$ & $11-15$ y1l & 12 & 7,8 \\
\hline 23-29 yaş & 66 & 42,9 & $\begin{array}{l}15 \text { yll ve üzeri } \\
\text { Toplam }\end{array}$ & $\begin{array}{c}6 \\
154\end{array}$ & $\begin{array}{l}3,9 \\
100\end{array}$ \\
\hline 30-35 yaş & 62 & 40,3 & $\begin{array}{c}\text { Toplam } \\
\text { çalışma süresi }\end{array}$ & Frekans & $\%$ \\
\hline $\begin{array}{l}36 \text { yaş ve üzeri } \\
\text { Toplam }\end{array}$ & $\begin{array}{c}26 \\
154 \\
\end{array}$ & $\begin{array}{l}16,8 \\
100 \\
\end{array}$ & $1-5$ y1l & 65 & 42,3 \\
\hline Medeni durum & Frekans & $\%$ & 6-10 y1l & 53 & 34,4 \\
\hline Evli & 78 & 49,4 & $11-15 \mathrm{y} 1 \mathrm{l}$ & 27 & 17,5 \\
\hline Bekar & 76 & 50,6 & 15 yıl ve üzeri & 9 & 5,8 \\
\hline Toplam & 154 & 100 & Toplam & 154 & 100 \\
\hline Eğitim & Frekans & $\%$ & $\begin{array}{c}\text { Kurumda } \\
\text { çalışan yakın }\end{array}$ & Frekans & $\%$ \\
\hline Lisans & 20 & 13,0 & Var & 28 & 18,2 \\
\hline Yüksek lisans & 70 & 45,5 & Yok & 126 & 81,8 \\
\hline Doktora & 64 & 41,5 & Toplam & 154 & 100 \\
\hline Toplam & 154 & 100 & & & \\
\hline
\end{tabular}

Tablo 2'de görüldüğü gibi; araştırmaya katılanların \%50,6's1 erkek, \%42,9'u 2329 yaş arasında, \%50,6'sı bekar, \%45,5'i yüksek lisans mezunu, \%61,7'si 1-5 yıl süreyle mevcut kurumlarında çalışmaktadır. Katılımcıların \%42,3'ü 1-5 yıl arası toplam çalışma süresine sahip olup \%81,8'inin aynı kurumda bir yakını çalışmamaktadır.

Araştırmada kullanılan veri setinin faktör analizine uygun olup olmadığını belirlemek amaciyla Kaiser-Meyer-Olkin (KMO) testi ve Bartlett testi kullanılmıştır. KMO değerinin 0,887 ve Bartlett testinin anlamlı $(p=0,00<0,05)$ 
olması nedeniyle veri setinin faktör analizi için oldukça uygun olduğu belirlenmiştir. Ölçeğin açıklayıcı faktör analizi sonuçları Tablo 3'te yer almaktadır.

Tablo 3: Açıklayıcı Faktör Analizi Sonuçları

\begin{tabular}{|c|c|c|c|c|c|}
\hline \multirow{2}{*}{$\begin{array}{c}\text { İfade } \\
\text { No }\end{array}$} & \multicolumn{4}{|c|}{ Faktör Bileșenleri } & \multirow{2}{*}{$\begin{array}{c}\text { Açıklanan } \\
\text { Varyans Oranı }\end{array}$} \\
\hline & Faktör 1 & Faktör 2 & Faktör 3 & Faktör 4 & \\
\hline İA3 &, 826 & & & & \multirow{7}{*}{10,133} \\
\hline İA2 & ,725 & & & & \\
\hline İA4 & ,682 & & & & \\
\hline İA1 & ,674 & & & & \\
\hline İA7 & ,654 & & & & \\
\hline İA5 & ,614 & & & & \\
\hline İA6 & ,523 & & & & \\
\hline DA1 & & ,898 & & & \multirow{4}{*}{5,600} \\
\hline DA2 & & ,851 & & & \\
\hline DA3 & & 817 & & & \\
\hline DA4 & & ,745 & & & \\
\hline EA3 & & & ,864 & & \multirow{9}{*}{41,088} \\
\hline EA2 & & & ,854 & & \\
\hline EA1 & & &, 840 & & \\
\hline EA9 & & & ,781 & & \\
\hline EA4 & & &, 776 & & \\
\hline EA5 & & & ,733 & & \\
\hline EA7 & & & ,732 & & \\
\hline EA6 & & & ,691 & & \\
\hline EA8 & & & ,678 & & \\
\hline İNT4 & & & & ,893 & \multirow{5}{*}{14,197} \\
\hline INT5 & & & & ,886 & \\
\hline İNT2 & & & & 872 & \\
\hline INTT1 & & & & ,862 & \\
\hline INT3 & & & & ,743 & \\
\hline
\end{tabular}

Tablo 3'te yer alan açıklayıcı faktör analizi sonucunda birinci faktör işlemsel adalet, ikinci faktör dağıtım adaleti, üçüncü faktör etkileşimci adalet ve dördüncü faktör intikam eğilimi olarak belirlenmiştir. Dört faktörün varyans açıklama oranının yaklaşık \%71 olduğu görülmektedir.

Araştırma kapsamında kullanılan ölçeğe ait güvenilirlik analizi sonuçları Tablo 4'te gösterilmiştir. 
Tablo 4: Faktör Analizi Öncesi ve Sonrası Güvenilirlik Analizi Sonuçları

\begin{tabular}{|c|c|c|c|}
\hline Ölçekler & Boyutlar & \multicolumn{2}{|c|}{$\begin{array}{c}\text { Cronbach Alfa }(\alpha) \\
\text { katsayıları }\end{array}$} \\
\hline \multirow{3}{*}{ Örgütsel adalet algısı } & İşlemsel adalet algisı & ,890 & \multirow{3}{*}{,945 } \\
\hline & Dağıtım adaleti algısı & ,901 & \\
\hline & Etkileşimsel adalet algisı & ,943 & \\
\hline İntikam niyeti & & \multicolumn{2}{|c|}{,917 } \\
\hline
\end{tabular}

Açıklayıcı faktör analizi sonrası tüm ölçeğin ve ölçekte yer alan alt boyutların güvenilirlikleri açısından Cronbach Alfa $(\alpha)$ katsayılarının 0,5'ten büyük olduğu görülmektedir. Bu doğrultuda, araştırmada kullanılan ölçeklerin oldukça güvenilir olduğu söylenebilir.

Açıklayıcı faktör analizinde (AFA) belirlenen faktör yapıları doğrulayıcı faktör analizine (DFA) tabi tutulmuştur. Birinci düzey DFA modeli oluşturularak ölçeğinin yapısındaki gizil faktörler ve bu faktörler arasındaki karşılıklı bağımlı etkiler test edilmiştir. İkili ilişkilere ait değerleri gösteren $p$ değerlerinin $p<0,05$ olması nedeniyle modelin istatistiksel olarak anlamlı olduğu görülmektedir. Standardize edilmiş tahmin sonuçlarına göre istatistiksel olarak anlamlı olduğu belirlenen modelin uyum indekslerinin $(\mathrm{x} 2=415,035, \mathrm{x} 2 / \mathrm{df}=1,584, \mathrm{CFI}=0,937$, RMSEA=0,070) uyum iyiliği indekslerini sağladığı görülmüştür.

Araştırmada yer alan örgütsel adalet değişkeninin alt boyutlarının intikam niyeti üzerindeki etkisini ölçebilmek amacıyla Lojistik Regresyon analizi kullanılmıştır. Lojistik regresyon analizinin kullanım amac1, istatistikte kullanılan diğer model yapılandırma tekniklerinde olduğu gibi bağımlı (yordanan) ve bağımsız (yordayıcı) değişkenler arasındaki ilişkiyi, en az değişken ile en iyi uyuma sahip olacak biçimde tanımlayabilen, kabul edilebilir bir model kurmaktır (Çokluk, 2010, s. 58). Lojistik Regresyon Analizi, sınıflama ve atama işlemi yapmaya yardımcı olan bir regresyon yöntemi olup, ayrıca doğrusal regresyon analizinden farklı olarak normal dağılım varsayımı, süreklilik varsayımı ön koşulunun olmaması daha kolay kullanım olanağı vermektedir (Güzel, Atilla Gök ve Büyüker İşler, 2013, s. 116-117).

Lojistik regresyon analizini uygulamadan önce ve sonra bağımlı değişken olan intikam niyeti sadece ikili düzeye sahip kesikli değişkene dönüştürülmüştür. Bu amaçla ölçeğin her bir katılımcı için intikam niyeti puanı hesaplanmıştır. Ölçeğin ortalaması maksimum 5; minimum 1 değerleri arasındadır. Anket katılımcılarının intikam niyeti ölçeğindeki sorulara verdikleri cevapların toplam puanı 1-10 puan arasında olanların intikam niyetine sahip olmadıkları ( 0 ile ifade edilmiş), 11 ve üzeri puana sahip olanların ise intikam niyetine sahip oldukları (1 ile ifade edilmiş) yönünde bir değerlendirme yapılmıştır. Yapılan bu düzenleme ile bağımlı 
değişken sadece 2 (iki) sonuca sahip olarak ikili (Binary) lojistik regresyon analizine uygun hale getirilmiştir.

Model seçimine karar verildikten sonra lojistik regresyon analizine başlamadan önce veriler taranarak uç değerler ve kayıp değerler açısından incelenmesi ve gerekli dönüştürmelerin yapılması gerekmektedir. Ayrıca analizde yordayıcı değişkenler arasında çoklu bağlantı (multicollinearity) sorunu olup olmadığının da incelenmesi gerekmektedir (Çokluk vd., 2012, s. 69-70). Çalışmada uç değer ve kayıp değer bulunmadığı için herhangi bir veri dönüştürme işlemi uygulanmamıştır. Çoklu bağlantı sorunu olup olmadığını test etmek için VIF (Varyans Artış Faktörleri) değerleri hesaplanmış ve değişkenlerin VIF değerlerinin tüm yordayıcı değişkenler için değerlerin 10'dan küçük olduğu saptanmıştır. Ortalama VIF değeri ise 1,808 'dir. Bu değerler değişkenler arası çoklu bağlantı probleminin olmadığını göstermektedir. Tablo 5 'te değişkenler arasındaki korelasyonlar ve VIF değerleri yer almaktadır.

Tablo 5: Araştırmada Yer Alan Değişkenler Arası Korelasyon ve VIF Değerleri

\begin{tabular}{l|l|c|c|c|c|c|}
\hline & \multicolumn{1}{|c|}{ Değişkenler } & $\mathbf{1}$ & $\mathbf{2}$ & $\mathbf{3}$ & $\mathbf{4}$ & VIF \\
\hline 1 & İntikam Niyeti & 1 & & & & - \\
\hline 2 & İşlemsel Adalet & $-0,195^{*}$ & 1 & & & 2,144 \\
\hline 3 & Dağıtım Adaleti & $-0,222^{*}$ & $0,554^{* *}$ & 1 & & 1,456 \\
\hline 4 & Etkileşim Adaleti & $-0,245^{* *}$ & $0,668^{* *}$ & $0,430^{* *}$ & 1 & 1,824 \\
\hline
\end{tabular}
$* 0,05$ anlamlılı düzeyinde.
$* 0,01$ anlamlılık düzeyinde.

Lojistik regresyon analizi tahmin edilen modelin uyumunu olabilirlik değerinin -2 logaritmasını (-2LL) alarak ölçmektedir. -2LL değeri sıfıra eşit olduğunda mükemmel uyum sağlanmış olmakla birlikte yordayıcı değişkenler modele eklendikçe, modelde meydana gelen gelişmeler ve model-veri uyumunda gözlenen iyileşmeler sonucunda -2LL değeri düşmektedir (Çokluk vd., 2012). Tablo 6'da yer alan -2LL değerinin 149,873 ile sıfır değerinden oldukça büyük olduğu görülmektedir.

Tablo 6: Başlangıç Modeli İterasyon Geçmişi

\begin{tabular}{|c|c|c|c|}
\hline \multicolumn{2}{|c|}{ İterasyon } & -2 Log Olabilirlik (-2LL) & Katsayılar \\
\hline Adım 0 & 1 & 149,873 & 0,733 \\
\hline & 2 & 149,840 & 0,769 \\
\hline & 3 & 149,840 & 0,769 \\
\hline
\end{tabular}

Sadece sabit terimin yer aldığı başlangıç tablosunda yapılan sınıflandırma tablosuna bakıldığında (Tablo 7) birinci aşamada toplam birimlerin \%68,3'nün doğru sınıflandırıldığ a anlaşılmaktadır. Lojistik regresyon analizinde bu 
değerlendirme yapılırken başlangıç modelde ancak bir gruba ait birimler doğru olarak sınıflandırılmaktadır (Kalaycı, 2010, s. 273-297). Çalışmada da katılımcıların tamamı intikam duygusuna sahip olduğu sınıfında yer almıştır.

Tablo 7: Başlangıç Modeli Sınıflandırma Tablosu

\begin{tabular}{|c|c|c|c|c|c|}
\hline Adım & \multicolumn{2}{|c|}{ Gözlenen } & \multicolumn{3}{c|}{ Tahmin Edilen } \\
\hline & \multicolumn{2}{|c|}{} & \multicolumn{2}{c|}{$\begin{array}{c}\text { İNTiKAM } \\
\text { NiYETİ }\end{array}$} \\
\hline \multirow{2}{*}{ Adım 0 0} & & Yok & Var & $\begin{array}{c}\text { Doğru Sinıflandırma } \\
(\%)\end{array}$ \\
\cline { 4 - 6 } & \multirow{2}{*}{$\begin{array}{c}\text { İNTIKAM } \\
\text { NiYETİ }\end{array}$} & Yok & 0 & 38 & 0 \\
\hline & \multicolumn{2}{|c|}{ Genel Yüzde } & 0 & 82 & 100 \\
\hline
\end{tabular}

Başlangıç modelini oluşturan sabit terime ait standart hata, değişkenin anlamlılığını test eden Wald istatistiği, Wald istatistiğinin anlamlılık düzeyi, serbestlik derecesi ve ilgili değişken bir birim artırıldığında üstünlük oranındaki değişimi gösteren $\operatorname{Exp}(\beta)$ değeri Tablo 8'de verilmektedir.

Tablo 8: Başlangıç Modelinde Yer Alan Değişkenler

\begin{tabular}{|c|c|c|c|c|c|c|}
\hline Adım 0 & $\boldsymbol{\beta}$ & S.H. & Wald & sd & p & $\operatorname{Exp(\beta )}$ \\
\hline Sabit & 0,769 & 0,196 & 15,361 & 1 & 0,000 & 2,158 \\
\hline
\end{tabular}

Başlangıç modelinde yer almayan değişkenler Tablo 9'da verilmektedir. Başlangıç modelde sadece sabit terim bulunduğu için modelde yer almayan değişkenlerin bir ya da birkaçının modele dahil olması durumunda modelde bir iyileşme olup olmayacağına yönelik olarak Tablo 9 incelendiğinde bağımsız değişkenlerin modele girmesi ile modelde herhangi bir iyileşme olmayacağı görülmektedir. Diğer bir ifade ile sabit terim dışında adalet algısı alt boyutlarının modele dahil olması ile intikam niyeti üzerinde önemli düzeyde bir etkiye sahip olacağı söylenememektedir.

Tablo 9: Modelde Yer Almayan Değişkenler

\begin{tabular}{|c|c|c|c|c|}
\hline & Değişkenler & Skor & sd & P \\
\hline \multirow{3}{*}{ Adım 0 } & İşlemsel Adalet & 0,860 & 1 & 0,354 \\
\cline { 2 - 5 } & $\begin{array}{c}\text { Dağıtım } \\
\text { Adaleti }\end{array}$ & 3,445 & 1 & 0,063 \\
\cline { 2 - 5 } & $\begin{array}{c}\text { Etkileşim } \\
\text { Adaleti }\end{array}$ & 1,596 & 1 & 0,206 \\
\hline \multicolumn{2}{|r}{ Hata $\chi^{2}$ İstatistiği } & 3,967 & 3 & 0,265 \\
\hline
\end{tabular}


Tablo 9'da yer alan p anlamlılık değerleri daha önceden belirlenen 0,05 anlamlılık düzeyi ile karşılaştırıldığında 0,05 değerinden daha küçük bir değer olmadığı için modelde bağımsız değişken olarak yer alan adalet algısı alt boyutlarından herhangi birisinin modelde bir iyileşme oluşturmayacağ 1 söylenebilir. Anlamlılık değeri $\mathrm{p}=0,063$ olan dağıtım adaleti alt boyutu diğer iki alt boyuta göre modelde iyileşme sağlayacak bir düzeydedir. Bağımsız değişkenlerin modele eklenmesiyle modelde herhangi bir iyileşme olması beklenmemesine karşın model veri uyumunu değerlendirmekte sonraki çalışmalar açısından fayda görülmektedir.

Lojistik regresyon analizinde, model-veri uyumunu belirleyebilmek amaciyla Hosmer-Lemeshow testi sonucunda elde edilen anlamlılık değerinin ( $p$ value) testin önceden belirlenen anlamlılık değeri $(0,05)$ ile karşılaştırılması gerekmektedir. $\mathrm{Bu}$ teste ilişkin sonucun anlamlı olmaması $(p>0,05)$, model-veri uyumunun yeterli düzeyde olduğunu göstermektedir (Çokluk vd., 2012, s. 100). Tablo 10'da yer alan Hosmer ve Lemeshow Test sonucu $\mathrm{p}=0,504>0,05$ olduğu için modelin kabul edilebilir bir uyuma sahip olduğu söylenebilir.

\section{Tablo 10: Hosmer ve Lemeshow Testi}

\begin{tabular}{|c|c|c|c|}
\hline Adım & Ki-Kare & sd & Anlamlılık (p) \\
\hline 1 & 7,301 & 8 & 0,504 \\
\hline
\end{tabular}

Lojistik regresyon analizinde modelin açıklayıcı gücüne yani bağımlı değişkenin yüzde kaçının bağımsız değişkenler tarafından açıklanabildiği de değerlendirilmektedir. Ancak bundan önce bağımsız değişkenlerin, bağımlı değişkeni açıklamada anlamlı olup olmadığına bakılması önemlidir (Güzel vd., 2013, s. 117).

Tablo 11: Model katsayılarının Anlamlılığı (Omnibus Testi)

\begin{tabular}{|l|l|c|c|c|}
\hline & & Ki-Kare & sd & $\begin{array}{c}\text { Anlamlılık } \\
\text { Değeri (p) }\end{array}$ \\
\hline \multirow{3}{*}{ Adım 1 } & Adım & 4,118 & 3 & 0,249 \\
\cline { 2 - 5 } & Blok & 4,118 & 3 & 0,249 \\
\cline { 2 - 5 } & Model & 4,118 & 3 & 0,249 \\
\hline
\end{tabular}

Model katsayılarının anlamlılığı (Omnibus) testinde model ki-kare değerine ilişkin p değerinin anlamlı olması, yordanan değişken ile yordayıcı değişkenler kombinasyonu arasında ilişkinin varlığını göstermektedir. Model ki-kare istatistiğinin anlamlı olması, "sadece sabit terimin yer aldığı başlangıç modeli ile yordayıcı değişkenlerin analize girmesiyle oluşan sonuç modeli ya da amaçlanan model arasında fark yoktur" şeklindeki null hipotezinin $\left(\mathrm{H}_{0}\right)$ reddedilmesi ve yordayıcı değişkenlerle yordanan değişken arasındaki ilişkinin desteklenmesini ifade etmektedir (Çokluk vd., 2012, s. 83). Tablo 11'de yer alan ki-kare değerleri 
ve anlamlılık değerleri incelendiğinde ki-kare değerlerinin anlamlı olmadığ diğer bir ifade ile yordayıcı değişkenlerin analize girmesiyle oluşan sonuç modeli ya da amaçlanan model arasında fark olmayacağı görülmektedir. Her ne kadar model katsayılarının anlamlılığı yordayıcı değişkenlerin modele girmesinde sabit model ile bir fark olmayacağı yönünde olsa da üçüncü olarak bağımlı değişskendeki değişikliklerin yüzde kaçının modelimizde ileri sürülen bağımsız değişkenler tarafından açıklandığının bakılmasında fayda görülmektedir.

Tablo 12: Amaçlanan Modelin Özeti

\begin{tabular}{|c|c|c|c|}
\hline Adım & -2 Log Olasılık & Cox \& Snell R & ${\text { Nagelkerke } \mathbf{R}^{\mathbf{2}}}^{\mathbf{2}}$ \\
\hline 1 & 145,721 & 0,034 & 0,047 \\
\hline
\end{tabular}

Regresyon analizindeki $\mathrm{R}^{2}$ istatistiğine benzediği geniş kabul gören ve bağımlı değişken ile bağımsız değişkenler arasındaki ilişkinin oranını temsil eden (Kalayc1, 2010, s. 273-297) Cox \& Snell $\mathrm{R}^{2}$ ve Nagelkerke $\mathrm{R}^{2}$ değerleri Tablo 12 'de görülmektedir. Tablo 12 'de yer alan model özet tablosu incelendiğinde lojistik regresyon analizine göre bağımlı değişken ile bağımsız değişkenler arasındaki ilişki Cox-Snell değeri \%3,4 ve Nagelkerke $\mathrm{R}^{2}$ değeri \%4,7'dir. Bu duruma göre katılımcıların intikam niyetine sahip olma ya da olmama davranışındaki değişikliklerin yalnızca \%4,7'si modeldeki bağımsız değişkenler (örgütsel adalet algısı boyutları) tarafından açıklanabilmektedir. $\mathrm{Bu}$ değerin oldukça düşük olduğu söylenebilir.

Sonuç olarak model veri uyumu sağlanmış olmakla birlikte adalet algısı boyutlarının intikam niyeti üzerinde önemli düzeyde bir etkiye sahip olmadığ 1 söylenebilir. Ancak çalışmanın örneklemi, örneklem büyüklüğü ve diğer sınırlılıklar göz önüne alınarak değerlendirildiğinde; örneklemin genişletilmesi ya da farklı örneklemlerde incelenmesi ile örgütsel adalet algısı boyutlarının intikam niyeti üzerinde etkili olabileceği ifade edilebilir.

\section{Sonuç}

Çalışma ortamında, çalışanları olumlu ya da olumsuz etkileyebilecek olay ya da durumlar gerçekleşebilmektedir. Örgüt içindeki adalet bu durumlardan biri olarak sayılabilmekte ve çalışanların tutum ve davranışlarını etkileyebilmektedir. Her çalışan adalet ve eşitliğin olduğu bir ortam talep etmektedir. Çalışma ortamında, adaletsiz bir davranış ya da eşitsiz bir uygulama fark edildiğinde, çalışanlar adaletsizliği ve eşitsizliği giderebileceğini düşünerek intikam niyeti içine girebilir. İntikam niyeti örgüte, intikam almak isteyene ve intikam alınmak istenene zarar verici sonuçlara neden olabilir. Bu nedenle örgütler için önemli olan adalet algısı alt boyutlarının intikam niyeti üzerine etkisi incelenmiş ve sonuç olarak araştırma görevlilerinin örgütsel adalet algısı alt boyutları ile intikam niyeti arasında istatistiksel olarak anlamlı bir ilişki bulunamamıştır. Güllü ve Şahin (2017) tarafından beden eğitimi ve spor öğretmenleri üzerinde gerçekleştirilen bir 
araştırmada bireylerin örgütsel adalet algısı ile örgütsel intikam eğilimleri arasında anlamlı ilişkinin olmadığı sonucuna varılmıştır. Bu doğrultuda kamu sektöründe yapılan ilgili çalışmaların sonuçlarının benzerlik gösterdiği belirtilebilir.

Aquino, Tripp ve Bies (2006) tarafından kamu sektöründe çalışanlar ile yapılan çalışmada ise işlemsel adalet ile intikam arasında ilişki bulunamamıştır. $\mathrm{Bu}$ çalışmanın aksine Law (2013) yarı zamanlı çalışan öğrenciler ile yapmış olduğu çalışmada işlemsel adaletin intikam niyetini etkileyen önemli bir örgütsel özellik olduğunu ortaya koymuştur. Dolayısıyla araştırmanın gerçekleştirildiği örneklemin özellikleri sonuçları etkileyebilmektedir.

Analiz sonuçlarına göre dağıtım adaletinin anlamlılık düzeyinin modeli iyileştirmeye yakın olduğu görülmüştür. Dağıtım adaletinin olmaması yani kazanımların adil dağıtılmamasının diğer alt boyutlara göre intikam niyetini daha çok etkileyeceği anlaşılmaktadır. İntikam niyetini, süreçler ve kişilerarası etkileşimlerdeki adaletten çok dağıtım adaletinin etkileyebileceği tespit edilmiş olup araştırma görevlileri için kazanımların adil bir şekilde dağıtılmasının önemli olduğu söylenebilir. Buradan hareketle, araştırma görevlileri arasında yetkilendirmede, sorumluluk vermede, ödüllendirmede, cezalandırmada, izin sürelerinde, okula geliş-gidiş saatlerinde, iş yükleri ve benzerlerinin dağıtılmasında adil davranılması ve bu unsurların düzenlenmesine özen gösterilmesinin önemli olduğu düşünülebilir. Çünkü Özer vd. (2014) tarafından yapılan çalışmada araştırma görevlilerinin intikam niyetlerinin işten ayrılma niyetini anlamlı bir şekilde etkilediği ortaya çıkarılmıştır. Dolayısı ile intikam niyetinin çalışanlar ve örgüt için olumsuz sonuçlar yaratacağ 1 göz önünde bulundurularak adaletli bir çalışma ortamın oluşturulmasının gerekli olduğu belirtilebilir.

Akademik örgütlerde örgütsel intikam ile yapılan çalışmalar oldukça az olmakla birlikte diğer sektörlerde konu ile ilgili çalışmalara rastlanmaktadır. Yılmaz (2014) 5 yıldızlı otel işletmeleri üzerinde yaptığı çalışmada mağduriyet algısında bir artış olduğunda intikam niyetinin arttığ Karacaoğlu vd. (2018), imalat sanayi işletmesinde çalışanların mağduriyet algıları ile işyeri arkadaşlık ilişkilerinin olumlu olmadığı durumlarda intikam niyetinin artacağı sonucuna ulaşmıştır. Bu sonuçların, intikamın mağduriyeti gidermeye yönelik bir davranış olduğunu desteklediği söylenebilir. Ayrıca Şantaş vd (2019) tarafından sağlık çalışanlarının incelendiği çalışmada ise katılımcıların intikam niyetlerinin düşük affetme eğilimlerinin yüksek olduğu bulgulanmıştır.

Araştırmada seçilen örneklemin kamu üniversitesinde çalışan araştırma görevlilerinden oluşması ve örnek birim sayısının da 154 katılımcı ile sınırlı olması analiz sonuçlarının genellemesi açısından yetersizdir. Ayrıca araştırma görevlileri üst mevkilerde yer alan öğretim üyeleri ile ne kadar anlaşamasalar da akademik örgütlerdeki hiyerarşik pozisyonlarından dolayı intikam alma 
davranışlarını gerçekleştiremeyebilirler. Bu durum kişilerin sahip oldukları güç kaynakları ile ilişkilendirilebilir. Zira kamu üniversitelerinde görev yapan araştırma görevlileri bulundukları kurumda hem öğrenimlerine devam etmekte hem de ileriye yönelik kadro beklentisi içinde olmaktadırlar. İntikam niyeti ile hareket etmeleri kendilerinin akademik anlamda ilerlemelerinde büyük sıkıntılara yol açabilecektir. Her ne kadar adaletsiz bir ortamda çalıştıklarını düşünseler de gelecek kaygısı ile bu düşüncelerini intikam niyetine yansıtmaktan çekinmektedirler. Algıladıkları mağduriyete karşılık intikam davranışında bulunamayan araştırma görevlilerinin kin tutma eğilimde olabilecekleri de söylenebilir. Nitekim Kıral ve Nayır (2018) yaptıkları araștırmada akademik örgütlerde her kademedeki kişilerin kin tutma eğilimde olduklarını bulgulamışlardır. Gerek intikam niyeti gerekse intikamı alamayıp kin tutmak hem bireyler hem de örgütler için olumsuz sonuçlar doğurabilir. Bu nedenle örgütlerde herkese eşit ve adaletli davranılmasının önemli olduğu düşünülebilir.

Araştırma sonuçlarının genele yayılabilmesi ve araştırmanın sınırlılıklarının kaldırılabilmesi için gelecek araştırmalarda evrenin genişletilmesi, örneklem büyüklügünün arttırılması hatta tüm örnekleme ulaşılabilmesi önemli görülmektedir. Ayrıca akademik örgütlerde araştırma görevlileri dışında diğer unvanlarda görev yapan öğretim üyelerine ulaşllarak unvanlar düzeyinde karşılaştırılma yapılması araştırmanın geliştirilmesi konusunda bir adım olarak belirtilebilir. Araştırmanın farklı sektörlerde yapılmasının ve çalışmanın ana kavramlarının farklı değişkenler ile ilişkilerinin incelenmesinin ilgili yazına katkı sağlayacağı düşünülmektedir. 


\section{Kaynakça}

Akanbi, P. A. ve Ofoegbu, O. E. (2013). Impact of perceived organizational justice on organizational commitment of a food and beverage firm in Nigeria. International Journal of Humanities and Social Science, 3 (14), 207-218.

Akın, M., Özdevecioğlu, M. ve Ünlü, O. (2012). Örgütlerde intikam niyeti ve affetme eğiliminin çalışanların ruh sağlıkları ile ilişkisi. Amme İdaresi Dergisi, 45 (1), 77-97.

Aquino, K., Tripp, T.M., ve Bies, R.J. (2006). Getting even or moving on? Power, procedural justice, and types of offense as predictors of revenge, forgiveness, reconciliation, and avoidance in organizations. Journal of Applied Psychology, 9(3), 653-668.

Bağcı, Z. (2013). Çalışanların örgütsel adalet algılarının örgütsel bağlılıkları üzerindeki etkisi: Tekstil sektöründe bir inceleme. Uluslararası Yönetim Iktisat ve Işsletme Dergisi, 9 (19), 163-184.

Bakhshi, A., Kumar, K. ve Rani E. (2009). Organizational justice perceptions as predictor of job satisfaction and organization commitment. International Journal of Business and Management, 4(9), 145-154.

Bies, R. J. ve Tripp, T. M. (2005). The study of revenge in the workplace: Conceptual, ideological, and empirical issues. Counter productive workplace behavior: An integration of both actor and recipient perspectives on causes and consequences. Fox, S. \& Spector, P.E. (Eds.). Washington, D.C.: APA Press.

Bies, R. J. ve Tripp, T. M. (2001). A passion for justice: The rationality and morality of revenge. Justice in workplace from theory to practice. Cropanzano, R. (Eds). London: Lawrence Earlbaum Associates Publishers.

Bies, R. J. ve Tripp, T. M. (1996). Beyond distrust "Getting even" and need for revenge. Trust in organizations: Frontiers of theory and research. Kramer, R. M. and Tyler, T. R. (Eds). USA: Sage Publications.

Bradfield, M. ve Aquino, K. (1999). The effects of blame attributions and offender likableness on forgiveness and revenge in the workplace. Journal of Management, 25 (5), 607-631.

Buluc, B. ve Gunes, A. M. (2014). Relationship between organizational justice and organizational commitment in primary schools. Anthropologist, 18 (1), $145-152$.

Cihangiroğlu, N. (2011). Askeri doktorların örgütsel adalet algıları ile örgütsel bağlılıkları arasındaki ilişkinin analizi. Gülhane Tıp Dergisi, 53, 9-16. 
Cohen, L., Manion, L. ve Morrison, K. (2007). Research methods in education, 6th Edition, New York: Routledge.

Colquitt, J. A. (2001). On the dimensionality of organizational justice: A construct validation of a measure. Journal of Applied Psychology, 86 (3), 386-400.

Colquitt, J. A., Conlon, D. E., Wesson, M. J., Porter, C. ve Ng, K. Y. (2001). Justice at the millennium: A meta-analytic review of 25 years of organizational justice research. Journal of Applied Psychology, 86 (3), 425445.

Cropanzano, R. ve Greenberg, J. (1997). Progress in organizational justice: Tunneling through the maze. International Review of Industrial and Orgnizational Psychology. C. L., Cooper \& I. T. Robertson (Eds.), New York: John Wiley\&Sons.

Çokluk, Ö. (2010). Lojistik regresyon analizi: Kavram ve uygulama. Kuram ve uygulamada eğitim bilimleri, 10 (3), 1357-1407.

Çokluk, Ö., Şekercioğlu, G. ve Büyüköztürk, Ş. (2012). Sosyal bilimler için çok değişkenli İstatistik SPSS ve LISREL uygulamaları. Ankara: Pegem Akademi.

Demiralay, T. (2014). Hekimlerde örgütsel sessizliğin yapısal eşitlik modeli ile incelenmesi. Basılmamış Doktora Tezi, Trakya Üniversitesi Sosyal Bilimler Enstitüsü.

Folger, R. ve Konovsky, M. A. (1989). Effects of procedural and distributive justice on reactions to pay raise decision. The Academy of Management Journal, 32 (1), 115-130.

Fox, S., Spector, P. E. ve Miles, D. (2001). Counterproductive work behavior (CWB) in response to job stressors and organizational justice: Some mediator and moderator tests for autonomy and emotions. Journal of Vocational Behavior, 59, 291-309.

Greenberg, J. (1990). Organizational justice: Yesterday, today and tomorrow" Journal of Management, 16 (2), 399-432.

Greenberg, J. (1993). The social side of fairness: Interpersonal and informational classes of organizational justice. Justice in the workplace: Approaching fairness in human resource Management, Cropanzano R. (Ed.), New Jersey: Lawrence Erlbaum.

Greenberg, J. ve Colquitt, J. A. (2005). Handbook of organizational justice, New Jersey: Lawrence Erlbaum.

Güllü, S. ve Şahin, S. (2017), Beden eğitimi ve spor öğretmenlerinin örgütsel adalet algısı ile örgütsel intikam (öç alma) eğilimi arasındaki ilişki. International Journal of Human Sciences, 14 (4), 3729-3741. 
Gürbüz, S. ve Mert, İ. S. (2009). Örgütsel adalet ölçeğinin geçerlik ve güvenirlik uygulaması: Kamuda görgül bir çalışma. Amme İdaresi Dergisi, 42 (3), 117139.

Güzel, F.Ö., Atilla Gök, G. ve Büyüker İşler, D. (2013). Duygusal emek ve işten ayrılma niyeti ilişkisi: Turist rehberleri üzerinde bir araştırma. Seyahat ve Otel İsletmeciliği Dergisi, 10 (3), 107-123.

İçerli, L. (2010). Örgütsel adalet: Kuramsal bir yaklaşım. Girişimcilik ve Kalkınma Dergisi, 5 (1), 67-92.

İnce, M. ve Gül, H. (2011). The effect of employees' perceptions of organizational justice on organizational citizenship behavior: An application in Turkish public institutions. International Journal of Business and Management, 6 (6), 134-149.

İyigün, N. Ö. (2012). Örgütsel adalet: Kuramsal bir yaklaşım. İstanbul Ticaret Üniversitesi Sosyal Bilimler Dergisi, 11 (21), 49-64.

Jena Abadi, H. ve Mobasheri, A. H. (2014). The study of organizational trust effect on organizational transparency and loyalty of primary school teachers in Zahedan City, Iran", World Applied Programming, 4 (6), 156-160.

Jones, D. (2009). Getting even with one's supervisor and one's organization: Relationships among types of injustice, desires for revenge, and counterproductive work behaviors. Journal of Organizational Behavior, 30, $525-542$.

Karacaoğlu, K., Aksoy, M. S. ve Şahin, S. (2018). Örgütlerde algilanan mağduriyetin intikam niyetine etkisinde işyeri arkadaşlığının düzenleyici rolü: Kayseri'de bir işletme uygulaması. 6. Örgütsel Davranış Kongresi Bildiriler Kitabı, Isparta.

Kalay, F. (2016). İşletmelerde örgütsel adaletin işgören performansı üzerindeki etkisi: Teorik bir inceleme. Kastamonu Üniversitesi Íktisadi ve İdari Bilimler Fakültesi Dergisi, 11, 147-158.

Kalayc1, Ş. (Ed.) (2010). SPSS uygulamalı çok değişkenli istatistik teknikleri. Ankara: Asil Yayın Dağıtım.

Kıral, B. ve Nayır, S. (2018). Akademisyen görüşlerine göre akademide kin tutma. Yükseköğretim Dergisi, 9(3), 290-302.

Latan, H. ve Ramli, N. A. (2014). The role of organizational justice, trust and commitment in a management control system (MCS)- Gain sharing. International Journal of Accounting and Financial Reporting, 4 (2), 186200.

Law, M. (2013). Exploring forgiveness: Do benevolence and revenge associate with procedural justice, workplace satisfaction and intention to leave? 
International Journal of Management Sciences and Business Research, 2(12), 167-179.

Little, L. M., Simmons, B. L. ve Nelson, D. L. (2007). Health among leaders: Positive and negative affect, engagement and burnout, forgiveness and revenge. Journal of Management Studies, 44 (2), 243-260.

Lowe, R. H. ve Vodanovich, S. J. (1995). A field study of distributive and procedural justice as predictors of satisfaction and organizational commitment. Journal of Business and Psychology, 10 (1), 99-114.

Luthans, F. (2011). Organizational behaviour: An evidence based approach, 12th Edition, New York: McGrawHill.

Mete, Y. A. ve Serin, H. (2014). Effect of perceived organizational justice and organizational trust on organizational commitment behavior. Journal of Educational Science Research, 4 (2), 265-286.

Moghimi, S. M., Kazemi, M. ve Samiie, S. (2013). Studying the relationship between organizational justice and employees' quality of work life in public organizations: A case study of Qom province. Iranian Journal of Management Studies (IJMS), 6 (1), 119-145.

Ngodo, O. E. (2008). Procedural justice and trust: The link in the transformational leadership - organizational outcomes relationship. International Journal of Leadership Studies, 4 (1), 82-100.

Özdevecioğlu, M. (2008). Organizasyonlarda intikam niyeti (Revenge intention) ve adalet algılamasının rolünü belirlemeye yönelik bir araştırma. 16. Ulusal Yönetim ve Organizasyon Kongre Kitabı, 381-385.

Özer, Ö., Sonğur, C., Kar, A., Top, M. ve Erigüç, G. (2014). Organizational stress, organizational cynicism, organizational revenge, intention to quit: Study on research assistants. The Macrotheme Review, 3 (8), 121-128.

Özer, P. S. ve Urtekin, G. E. (2007). Örgütsel adalet algısı boyutları ve iş doyumu ilişkisi üzerine bir araştırma. Erciyes Üniversitesi İktisadi ve İdari Bilimler Fakültesi Dergisi, 28, 107-125.

Özmen, Ö. N., Arbak, Y. T. ve Özer, P. S. (2007). Adalete verilen değerin adalet algıları üzerindeki etkisinin sorgulanmasına ilişkin bir araştırma. Ege Akademik Bakış, 7 (1), 17-33.

Paterson, J. M., Green, A. ve Cary, J. (2002). The measurement of organizational justice in organizational change programmes: A reliability, validity and context-sensitivity assessment. Journal of Occupational and Organizational Psychology, 75, 393-408.

Pelit, E. ve Bozdoğan, İ. (2014). Çalışanların örgütsel adalet algılamalarının tükenmişlik düzeyleri üzerindeki etkisi: Kemer'deki beş yıldızlı otel işletmelerinde bir uygulama. Iş̧letme Araştırmaları Dergisi, 6 (2), 37-66. 
Radmanesh, S. (2015). The impact of organizational justice on organizational loyalty considering the role of spirituality trust variables (Case study: South Pars Gas Complex). Joint International Conference, 27-29 May, Italy.

Rai, G. S. (2013). Impact of organizational justice on satisfaction, commitment and turnover intention: Can fair treatment by organizations make a difference in their workers' attitudes and behaviors?. International Journal of Human Science, 10 (2), 260-284.

Sjahruddin, H., Sudiro, A. A. ve Normijati (2013). Organizational justice, organizational commitment and trust in manager as predictor of organizational citizenship behavior. Interdisciplinary Journal of Contemporary Research in Business, 4 (12), 133-141.

Stillwell, A. M., Baumeister, R. F. ve Priore, R. E. D. (2008). We're all victims here: Toward a psychology of revenge. Basic and Applies Social Psychology, 30, 253-263.

Stuckless, N. ve Goranson, R. (1992). The Vengeance scale: Development of a measure of attitudes toward revenge. Journal of Social Behaviour and Personality, 7 (1), 25-47.

Şantaş, G., Akbolat, M. ve Sağlam, H. (2019). Sağlık çalışanlarında örgütsel affetme ve örgütsel dedikodunun intikam niyeti üzerindeki etkisi", Pamukkale Üniversitesi Sosyal Bilimler Enstitüsü Dergisi, 36, 131-148.

Şener, E., Çetinkaya, F. F. ve Akkoca, Y. (2017). Hidden side of the employee relations: The relationship between impression management and revenge intention. International Journal of Business and Management Invention, 6(7), 73-84.

Tokgöz, N. (2011). Örgütsel sinisizm, örgütsel destek ve örgütsel adalet ilişskisi: Elektrik dağıtım işletmesi çalışanları örneği. Eskişehir Osmangazi Üniversitesi İIBF Dergisi, 6 (2), 363-387.

Tripp, T. M., Bies, R. J. ve Aquino, K. (2007). A Vigilante model of justice: Revenge, reconciliation, forgiveness, and avoidance. Social Justice Research, 20 (1), 10-34.

Wade, S. H. (1989). The development of a scale to measure forgiveness. Unpublished Doctoral Dissertation, California: Fuller Theological Seminary.

Yılmaz, Ö. D. (2014). Algılanan mağduriyetin affetme eğilimi ve intikam niyeti üzerindeki etkisi: Konaklama işletmeleri çalışanlarına yönelik bir araştırma. AKÜ İ̈BF dergisi, XVI (1), 87-105. 


\section{A Research on Determining the Relationship between Organizational Justice Perception and Revenge Intention in Organizations}

\section{Extended Abstract}

\section{Introduction}

One of the most researched topics in the scientific areas of industrial and organizational psychology, human resources management and organizational behavior is the notion of organizational justice, which means the employees' perception of justice in organizations. Satisfaction of employees is necessary to gain their commitment and loyalty to the organization and the organization needs to establish a fair system in order to achieve these.

In the event that the environment of justice cannot be created within the organization, employees might exhibit negative attitudes and behaviors towards the organization. It can be said that the intention of revenge is one of these attitudes and behaviors. Revenge has physical and emotional negative consequences for both the faulty and the victim. It is possible to talk about the necessity of an organizational environment with equality and justice in order to prevent negative results at personal and organizational level.

It is necessary to take into consideration that there may be something going wrong at some points and make changes to eliminate them when it is understood that the employee has a revenge intention in the organization. In this respect, it can be stated that revenge intention might be an indicator for the improvement of the organization.

Based on the relationship between the two notions, this study aims to reveal the effect of employees' perception of organizational justice on revenge intentions.

\section{Method}

The population of the research consists of research assistants who are working at faculties and colleges of a state university. The research sample consists of 154 research assistants who were selected by sampling method and accepted to participate in the study.

Survey method was used to collect data in the research. The questionnaire used consists of three parts. In the first and second part of the questionnaire, 5 -point Likert $(1=$ strongly disagree.... $5=$ strongly agree) 20-items organizational justice scale and 5-items revenge intention scale to was used to determine the revenge intention and perception of organizational justice of individuals. In the third part of the questionnaire, 5 questions were asked to determine the demographic characteristics of the participants.

The effect of participatory procedural justice, distributive justice and transactional justice perception on revenge intention were examined in this study. In line with the model, the hypotheses to be tested in the research were presented. The data obtained from the questionnaire applied to the research assistants were evaluated by using SPSS 22.0 and AMOS 23 package programs and the results were interpreted. Explanatory and confirmatory factor analysis and logistic regression analysis were used to obtain the results. 


\section{Results and Discussion}

As a result, there was no statistically significant relationship between the perception of organizational justice and revenge intention. Only $4.7 \%$ of the changes in the behavior of participants with or without revenge intention can be explained by independent variables (organizational justice perception dimensions) in the model. This value can be said to be very low.

According to the results of the analysis, the level of significance of distributive justice is close to improve the model. It was found that the lack of distributive justice, that is, the fair distribution of the gains, will affect the revenge intention more than other sub-dimensions. When the sample of the study was evaluated considering the sample size and other limitations; it can be stated that the dimensions of organizational justice perception may have an effect on the revenge intention by expanding the sample or examining it in different samples.

Although the model data fit was achieved, it can be said that the perception of organizational justice does not have a significant effect on the revenge intention. In a study conducted by Güllü and Sahin (2017) on physical education and sports teachers, it was concluded that there is no significant relationship between individuals' perception of organizational justice and organizational revenge tendencies. It is similar to the results obtained from this study.

\section{Conclusion}

According to the results of the analysis, no statistically significant relationship was found between the research assistants' revenge intentions and organizational justice perceptions, but it was determined that the revenge intention can be affected by distributive justice rather than justice in processes and interpersonal interactions. It can be said that it is important for research assistants to distribute the gains fairly. From this point of view, it is important to behave fairly and to pay attention to the regulation of elements such as authorization, giving responsibility, rewarding, punishment, leave periods, arrival and departure times at work, distribution of workloads among the research assistants. Because Özer et al. (2014) revealed that the revenge intention of research assistants significantly affected the intention of leave. Therefore, it can be stated that it is necessary to establish a fair environment considering that the revenge intention will have negative consequences for the employees and the organization.

The fact that the sample selected in the research consists of research assistants working at public university and the number of sample units is limited to 154 participants is insufficient in terms of generalizing the results of the analysis. Because research assistants working at public universities continue their education at the institution and expect to be the future staff there. Acting with the revenge intention may cause great difficulties for their academic progress. Even though they think that they work in an unfair environment, they are afraid to reflect these thoughts on the revenge intention because of concern for the future.

It is essential to expand the population, increase the sample size and even reach the whole sample in order to disseminate the results of the research in general and to remove the limitations of the research. In addition, it is thought that conducting the research in different sectors and examining the relationship between the notions of the study and different variables will contribute to the related literature. 